\title{
COMMENTARY
}

\section{Child Immunization Cards: Essential Yet Underutilized in National Immunization Programmes}

\author{
David W. Brown*
}

United Nations Children's Fund (UNICEF), Three United Nations Plaza, New York, 10017, USA

\begin{abstract}
The child immunization card is an inexpensive yet effective instrument for systematically recording the vaccines received by a child. Moreover, the card can enhance health professionals' ability to make clinical decisions, empower parents/caregivers in the health care of their children, and support public health monitoring. Unfortunately, the child immunization card is too often underutilized or inappropriately used by parents and health care workers and therefore does not always fulfil its intended purpose. National immunization programmes should be encouraged to procure cards in conjunction with other necessary vaccination supplies and to more actively promote the issuance and appropriate use of the card.
\end{abstract}

Keywords: Immunization cards, immunization, recording, monitoring.

\section{INTRODUCTION}

Monitoring childhood immunization status is an important public health activity. In many countries, a child's immunization status is recorded in registries, sometimes electronic and often not, that are maintained at health facilities. Although registers provide a potentially important source of information for assessing trends, responding to emerging threats and guiding development of policies and interventions, registers are often not used in outreach activities to identify unimmunized children and at times are difficult to use to trace back a child's immunization history. Fortunately, the child immunization card, one of the most simple personal health records available, can be used to fill these gaps.

Child immunization cards provide a systematized way of recording the vaccines received by children as recommended by national and international health authorities [1]. More importantly, the child immunization card is a point-ofcare information resource that can (1) enhance health professionals' ability to make clinical decisions and prevent unnecessary repetition of vaccination, (2) empower parents/caregivers in the health care of their children, and (3) support public health monitoring.

The successful utilization of child immunization cards by national immunization programmes requires that the card be issued to parents (caregivers) at the birth of the child or at the first contact with a vaccinator/health care worker and that the card be retained and brought to each encounter the child has with the health care system. As such, information would be collected at all health consultations including sick- and well-visits conducted at a health clinic/post as well as any

\footnotetext{
*Address correspondence to this author at the United Nations Children's Fund (UNICEF), Three United Nations Plaza, New York, 10017, USA; Tel: +1.212.303.79.88; E-mail: dbrown at unicef dot org
}

supplementary immunization activity (e.g., a measles campaign in a village), although presentation of cards at the latter is rarely practiced. Finally, the successful use of the card requires that all health care workers, who come into contact with the child, reference the card and accurately and legibly update the card so that the information on the card is correctly interpreted and translated into appropriate medical advice and action [2].

When properly used, child immunization cards provide a relatively inexpensive and effective instrument in the promotion of childhood immunization and child health more generally [3]. In addition, the cards allow the addition of essential health information including a record of birth data such as the birth date and birth weight, a visual record of the child's growth, factors that may affect the child's ability to develop normally or adapt to a new environment, as well as a continuous and permanent record of the child's development by recording the medical and social history. These more comprehensive child health cards are viewed by many as advantageous because they inherently emphasise the place of immunization within the context of the child's overall health and development rather than being viewed as an end in itself [4]. Regardless of type (immunization card or health card), the utilization of cards has been associated with improvements in the uptake of preventive health services, such as immunizations [5], and with up-to-date [6] and fully immunized $[7,8]$ children as well as serving as a reference for health care workers [9].

Immunization cards also have an important role in improving parental awareness and involvement in their child's health care. Research has shown that missed opportunities for immunization are often the result of parental lack of awareness of the benefits of vaccines as well as a lack of awareness of the vaccination schedule and when their child is due for his/her next vaccine [10,11]. Although most cards incorporate such information, opportunities 
Table 1. Prevalence (\%) of Immunization or Health Cardholders at the Time of Survey by Select Background Characteristics in 87 Countries with a DHS or MICS Survey, 2000-2010

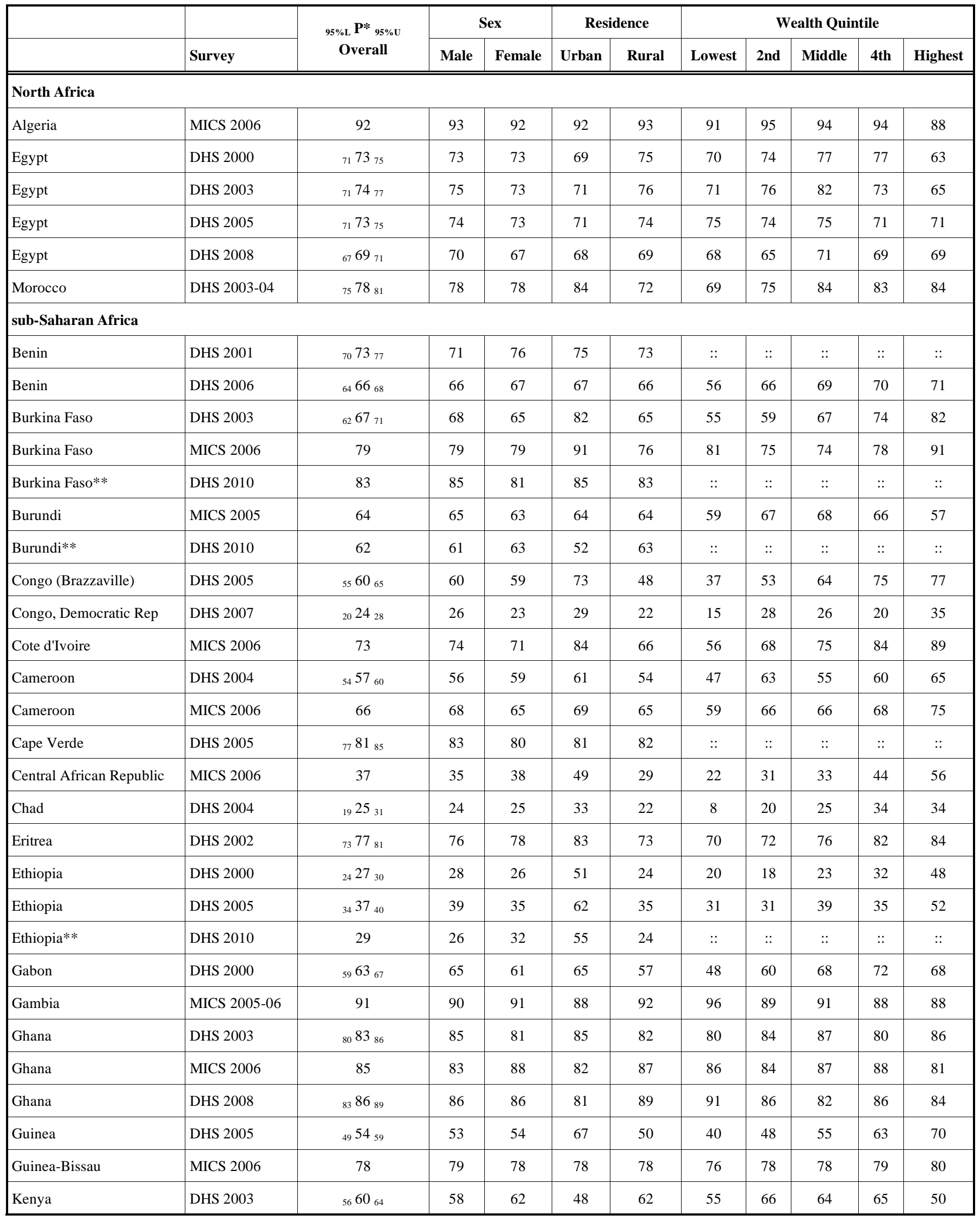


Table 1. contd...

\begin{tabular}{|c|c|c|c|c|c|c|c|c|c|c|c|}
\hline & \multirow[b]{2}{*}{ Survey } & \multirow{2}{*}{$\begin{array}{c}95 \% \mathrm{~L} \mathbf{P}^{*}{ }_{95 \% \mathrm{U}} \\
\text { Overall }\end{array}$} & \multicolumn{2}{|c|}{ Sex } & \multicolumn{2}{|c|}{ Residence } & \multicolumn{5}{|c|}{ Wealth Quintile } \\
\hline & & & Male & Female & Urban & Rural & Lowest & 2nd & Middle & 4th & Highest \\
\hline Kenya & DHS 2008-09 & 70 & 69 & 72 & 55 & 75 & 72 & 75 & 80 & 72 & 56 \\
\hline Lesotho & DHS 2004 & 747882 & 77 & 78 & 78 & 78 & 73 & 74 & 78 & 85 & 79 \\
\hline Liberia & DHS 2007 & ${ }_{43} 4853$ & 45 & 51 & 58 & 43 & 35 & 38 & 55 & 57 & 59 \\
\hline Madagascar & DHS 2003-04 & ${ }_{44} 50_{56}$ & 46 & 54 & 55 & 49 & 35 & 50 & 52 & 64 & 60 \\
\hline Madagascar & DHS 2008-09 & ${ }_{57} 6063$ & 60 & 61 & 71 & 59 & 46 & 58 & 64 & 69 & 74 \\
\hline Malawi & MICS 2006 & 77 & 78 & 76 & 80 & 76 & 74 & 78 & 77 & 78 & 79 \\
\hline Mali & DHS 2001 & ${ }_{45} 488_{51}$ & 48 & 48 & 64 & 43 & 41 & 42 & 40 & 51 & 71 \\
\hline Mali & DHS 2006 & ${ }_{58} 61_{64}$ & 64 & 58 & 62 & 60 & 63 & 59 & 62 & 59 & 63 \\
\hline Mauritania & DHS 2000-01 & ${ }_{30} 3438$ & 35 & 34 & 39 & 31 & 29 & 36 & 35 & 27 & 47 \\
\hline Mauritania & MICS 2007 & 32 & 31 & 34 & 31 & 33 & 31 & 38 & 34 & 29 & 31 \\
\hline Mozambique & DHS 2003 & 757881 & 79 & 77 & 86 & 75 & 64 & 80 & 78 & 86 & 90 \\
\hline Mozambique & MICS 2008 & 85 & 85 & 85 & 90 & 83 & 78 & 81 & 87 & 89 & 91 \\
\hline Nigeria & DHS 2008 & ${ }_{24} 2628$ & 26 & 26 & 39 & 21 & 8 & 17 & 26 & 36 & 52 \\
\hline Rwanda & DHS 2000 & ${ }_{63} 66_{69}$ & 68 & 64 & 64 & 67 & 65 & 66 & 64 & 68 & 68 \\
\hline Rwanda & DHS 2005 & ${ }_{73} 76_{79}$ & 75 & 77 & 69 & 77 & 71 & 77 & 78 & 78 & 75 \\
\hline Rwanda & DHS 2007-08 & ${ }_{63} 6771$ & 65 & 69 & 64 & 68 & 66 & 68 & 70 & 67 & 62 \\
\hline Sao Tome and Principe & MICS 2006 & 91 & 88 & 93 & 87 & 95 & 93 & 93 & 94 & 86 & 88 \\
\hline Sao Tome and Principe & DHS 2008-09 & 909396 & 92 & 95 & 92 & 94 & 90 & 91 & 97 & $::$ & 94 \\
\hline Senegal & DHS 2005 & $6770_{73}$ & 70 & 70 & 69 & 71 & 71 & 67 & 71 & 70 & 72 \\
\hline Sierra Leone & MICS 2005 & 53 & 54 & 52 & 50 & 54 & 42 & 48 & 60 & 60 & 53 \\
\hline Sierra Leone & DHS 2008 & ${ }_{57} 6063$ & 61 & 59 & 58 & 61 & 58 & 64 & 61 & 58 & 58 \\
\hline Somalia & MICS 2006 & 8 & 10 & 6 & 15 & 4 & 3 & 4 & 11 & 10 & 12 \\
\hline South Africa & DHS 2003 & 657177 & 71 & 71 & 67 & 79 & $::$ & $::$ & $::$ & $::$ & $::$ \\
\hline Swaziland & DHS 2006-07 & 818487 & 84 & 84 & 75 & 86 & 89 & 85 & 83 & 86 & 77 \\
\hline Tanzania, United Rep. & DHS 2004-05 & 767982 & 78 & 80 & 79 & 79 & 75 & 77 & 80 & 85 & 78 \\
\hline Tanzania, United Rep. & DHS 2010 & 828487 & 84 & 85 & 85 & 84 & 82 & 87 & 83 & 85 & 85 \\
\hline
\end{tabular}


Table 1. contd....

\begin{tabular}{|c|c|c|c|c|c|c|c|c|c|c|c|}
\hline & \multirow[b]{2}{*}{ Survey } & \multirow{2}{*}{$\begin{array}{c}{ }_{95 \% \mathrm{~L}} \mathbf{P} *{ }_{95 \% \mathrm{U}} \\
\text { Overall }\end{array}$} & \multicolumn{2}{|c|}{ Sex } & \multicolumn{2}{|c|}{ Residence } & \multicolumn{5}{|c|}{ Wealth Quintile } \\
\hline & & & Male & Female & Urban & Rural & Lowest & 2nd & Middle & 4th & Highest \\
\hline \multicolumn{12}{|l|}{ sub-Saharan Africa } \\
\hline Togo & MICS 2006 & 70 & 69 & 72 & 77 & 66 & 64 & 61 & 72 & 77 & 80 \\
\hline Uganda & DHS 2000-01 & ${ }_{44} 4750$ & 48 & 47 & 43 & 48 & 48 & 46 & 49 & 47 & 48 \\
\hline Uganda & DHS 2006 & ${ }_{60} 6366$ & 64 & 62 & 63 & 63 & 59 & 67 & 66 & 62 & 59 \\
\hline Zambia & DHS 2001-02 & ${ }_{77} 80_{83}$ & 78 & 81 & 81 & 79 & $::$ & $::$ & $::$ & $::$ & $::$ \\
\hline Zambia & DHS 2007 & ${ }_{75} 7881$ & 79 & 77 & 79 & 78 & 80 & 79 & 74 & 77 & 80 \\
\hline Zimbabwe & DHS 2005-06 & ${ }_{69} 72_{75}$ & 69 & 76 & 75 & 71 & 70 & 70 & 73 & 75 & 75 \\
\hline \multicolumn{12}{|c|}{ Caribbean and Latin America } \\
\hline Belize & MICS 2006 & 64 & 73 & 54 & 65 & 63 & $::$ & $::$ & $::$ & $::$ & $::$ \\
\hline Bolivia & DHS 2003 & 777981 & 77 & 80 & 79 & 79 & 75 & 82 & 79 & 82 & 75 \\
\hline Bolivia & DHS 2008 & 747780 & 78 & 75 & 79 & 74 & 72 & 78 & 79 & 80 & 75 \\
\hline Colombia & DHS 2000 & 727578 & 75 & 74 & 76 & 71 & $::$ & $::$ & $::$ & $::$ & $::$ \\
\hline Colombia & DHS 2005 & 767880 & 80 & 76 & 80 & 74 & 73 & 75 & 83 & 80 & 83 \\
\hline Colombia & DHS 2010 & ${ }_{81} 8385$ & 84 & 82 & 82 & 85 & 84 & 86 & 84 & 82 & 77 \\
\hline Cuba & MICS 2006 & 98 & 98 & 97 & 97 & 99 & $::$ & $::$ & $::$ & $::$ & $::$ \\
\hline Dominican Republic & DHS 2002 & ${ }_{47} 50_{53}$ & 49 & 51 & 50 & 51 & 44 & 46 & 55 & 55 & 54 \\
\hline Dominican Republic & DHS 2007 & ${ }_{59} 62{ }_{65}$ & 61 & 63 & 61 & 64 & 59 & 57 & 61 & 69 & 67 \\
\hline Guyana & MICS 2006-07 & 75 & 71 & 80 & 76 & 75 & 72 & 71 & 80 & 78 & 78 \\
\hline Guyana & DHS 2009 & ${ }_{83} 8892$ & 87 & 88 & 85 & 88 & 84 & 91 & 92 & 88 & 87 \\
\hline Haiti & DHS 2000 & ${ }_{61} 66_{71}$ & 67 & 66 & 70 & 64 & 59 & 60 & 74 & 63 & 80 \\
\hline Haiti & DHS 2005-06 & ${ }_{69} 7377$ & 75 & 71 & 77 & 71 & 67 & 72 & 74 & 72 & 83 \\
\hline Honduras & DHS 2005-06 & ${ }_{83} 8587$ & 85 & 85 & 80 & 88 & 90 & 87 & 86 & 81 & 77 \\
\hline Jamaica & MICS 2005 & 74 & 76 & 72 & 72 & 76 & $::$ & $::$ & $::$ & $::$ & $::$ \\
\hline Nicaragua & DHS 2001 & ${ }_{76} 7982$ & 80 & 77 & 77 & 80 & 77 & 82 & 83 & 78 & 72 \\
\hline Peru & DHS 2000 & 555861 & 59 & 57 & 63 & 52 & 53 & 56 & 60 & 66 & 60 \\
\hline Peru & DHS 2004 & ${ }_{61} 67_{72}$ & 65 & 68 & 69 & 63 & 62 & 68 & 72 & 57 & 81 \\
\hline Peru & DHS 2004-06 & ${ }_{63} 66_{70}$ & 68 & 65 & 67 & 65 & 67 & 65 & 69 & 57 & 79 \\
\hline Peru & DHS 2007-08 & ${ }_{59} 6366$ & 65 & 61 & 62 & 64 & 63 & 70 & 60 & 56 & 62 \\
\hline Peru & DHS 2009 & ${ }_{63} 66_{69}$ & 67 & 65 & 66 & 66 & 68 & 68 & 62 & 66 & 65 \\
\hline Peru & DHS 2010 & 737678 & 77 & 74 & $::$ & $::$ & 80 & 76 & 78 & 74 & 67 \\
\hline Suriname & MICS 2006 & 81 & 79 & 83 & 81 & $::$ & 79 & 87 & 86 & 79 & 77 \\
\hline Trinidad and Tobago & MICS 2006 & 79 & 77 & 81 & $::$ & $::$ & $::$ & $::$ & 77 & $::$ & $::$ \\
\hline \multicolumn{12}{|c|}{ Caucasus and Central Asia } \\
\hline Armenia & DHS 2000 & 919497 & $::$ & $::$ & 93 & 96 & $::$ & $::$ & $::$ & $::$ & $::$ \\
\hline Armenia & DHS 2005 & ${ }_{87} 9297$ & 94 & 89 & 92 & 91 & 91 & 92 & 96 & 93 & $::$ \\
\hline Armenia** & DHS 2010 & 92 & 91 & 94 & 90 & 96 & $::$ & $::$ & $::$ & $::$ & $::$ \\
\hline Azerbaijan & DHS 2006 & ${ }_{66} 72{ }_{78}$ & 79 & 65 & 75 & 70 & 57 & 72 & 82 & 67 & 86 \\
\hline
\end{tabular}


Table 1. contd...

\begin{tabular}{|c|c|c|c|c|c|c|c|c|c|c|c|}
\hline & \multirow[b]{2}{*}{ Survey } & \multirow{2}{*}{$\begin{array}{c}{ }_{95 \% \mathrm{~L}} \mathbf{P}^{*}{ }_{95 \% \mathrm{U}} \\
\text { Overall }\end{array}$} & \multicolumn{2}{|c|}{ Sex } & \multicolumn{2}{|c|}{ Residence } & \multicolumn{5}{|c|}{ Wealth Quintile } \\
\hline & & & Male & Female & Urban & Rural & Lowest & 2nd & Middle & 4th & Highest \\
\hline \multicolumn{12}{|c|}{ Caucasus and Central Asia } \\
\hline Kazakhstan & MICS 2006 & 95 & 96 & 95 & 97 & 93 & 96 & 95 & 93 & 96 & 96 \\
\hline Tajikistan & MICS 2005 & 83 & 85 & 81 & 85 & 82 & 81 & 86 & 81 & 84 & 84 \\
\hline Turkmenistan & DHS 2000 & 94 & 94 & 94 & 89 & 98 & 99 & 99 & 95 & 91 & 87 \\
\hline Uzbekistan & MICS 2006 & 96 & 96 & 96 & 92 & 98 & 97 & 98 & 97 & 96 & 92 \\
\hline \multicolumn{12}{|l|}{ Western Asia } \\
\hline Iraq & MICS 2006 & 55 & 58 & 53 & 61 & 47 & $::$ & $::$ & $::$ & $::$ & $::$ \\
\hline Jordan & DHS 2002 & 757881 & 77 & 78 & 76 & 84 & 85 & 81 & 79 & 73 & 58 \\
\hline Jordan & DHS 2007 & ${ }_{88} 9092$ & 88 & 92 & 91 & 87 & 91 & 92 & 90 & 90 & 85 \\
\hline Turkey & DHS 2003 & ${ }_{49} 5459$ & 57 & 51 & 63 & 34 & $::$ & $::$ & $::$ & $::$ & $::$ \\
\hline Yemen & MICS 2006 & 48 & 50 & 47 & 51 & 47 & 44 & 39 & 44 & 55 & 62 \\
\hline \multicolumn{12}{|l|}{ Southern Asia } \\
\hline Bangladesh & DHS 2004 & ${ }_{46} 49{ }_{52}$ & 47 & 52 & 58 & 47 & 44 & 46 & 48 & 52 & 61 \\
\hline Bangladesh & MICS 2006 & 66 & 66 & 65 & 66 & 65 & 62 & 64 & 68 & 68 & 66 \\
\hline Bangladesh & DHS 2007 & ${ }_{54} 58_{62}$ & 58 & 58 & 60 & 58 & 62 & 54 & 56 & 63 & 56 \\
\hline India & DHS 2005-06 & ${ }_{36} 38_{40}$ & 39 & 36 & 46 & 35 & 26 & 32 & 39 & 43 & 56 \\
\hline Maldives & DHS 2009 & ${ }_{86} 8992$ & 88 & 90 & 85 & 91 & 92 & 93 & 89 & 86 & 85 \\
\hline Nepal & DHS 2001 & ${ }_{14} 16_{18}$ & 17 & 15 & 18 & 16 & 11 & 16 & 16 & 20 & 22 \\
\hline Nepal & DHS 2006 & ${ }_{27} 32_{37}$ & 34 & 30 & 43 & 30 & 23 & 29 & 36 & 35 & 43 \\
\hline Nepal & DHS 2010 & 34 & 38 & 30 & 39 & 33 & $::$ & $::$ & $::$ & $::$ & $::$ \\
\hline Pakistan & DHS 2006-07 & ${ }_{21} 24_{27}$ & 24 & 24 & 26 & 23 & 13 & 20 & 26 & 26 & 36 \\
\hline \multicolumn{12}{|c|}{ South-Eastern Asia } \\
\hline Cambodia & DHS 2000 & ${ }_{44} 48_{52}$ & 47 & 49 & 49 & 47 & 42 & 40 & 44 & 54 & 70 \\
\hline Cambodia & DHS 2005 & ${ }_{64} 67_{70}$ & 69 & 64 & 63 & 67 & 57 & 69 & 66 & 73 & 73 \\
\hline Indonesia & DHS 2002-03 & ${ }_{28} 31_{34}$ & 30 & 32 & 32 & 30 & 23 & 25 & 39 & 34 & 34 \\
\hline Indonesia & DHS 2007 & ${ }_{34} 37_{40}$ & 38 & 36 & 38 & 36 & 26 & 36 & 38 & 46 & 39 \\
\hline Lao PDR & MICS 2006 & 49 & 48 & 50 & 56 & $44.2-49.2$ & 41 & 44 & 60 & 53 & 55 \\
\hline Philippines & DHS 2003 & ${ }_{36} 39_{42}$ & 41 & 36 & 38 & 40 & 32 & 46 & 47 & 37 & 32 \\
\hline Philippines & DHS 2008 & 43 & 43 & 42 & 43 & 42 & 37 & 43 & 45 & 47 & 42 \\
\hline Thailand & MICS 2005-06 & 88 & 89 & 87 & 85 & 90 & 90 & 93 & 85 & 90 & 82 \\
\hline Timor-Leste & DHS 2009-10 & ${ }_{47} 50_{53}$ & 52 & 47 & 44 & 52 & 43 & 51 & 52 & 57 & 45 \\
\hline Vietnam & DHS 2002 & ${ }_{34} 40_{46}$ & 40 & 40 & 59 & 36 & 24 & 38 & 39 & 38 & 68 \\
\hline Vietnam & MICS 2006 & 38 & 36 & 42 & 54 & 34 & $::$ & $::$ & $::$ & $::$ & $::$ \\
\hline \multicolumn{12}{|l|}{ Eastern Asia } \\
\hline Mongolia & MICS 2005 & 81 & 81 & 80 & 79 & 82 & 76 & 80 & 89 & 81 & 77 \\
\hline \multicolumn{12}{|l|}{ Oceania } \\
\hline Vanuatu & MICS 2007 & 69 & 67 & 71 & 66 & 69 & 65 & 71 & 66 & 75 & $::$ \\
\hline
\end{tabular}


Table 1. contd....

\begin{tabular}{|c|c|c|c|c|c|c|c|c|c|c|c|}
\hline & Survey & $\begin{array}{c}95 \% \mathrm{~L} \mathrm{P}^{*}{ }_{95 \% \mathrm{U}} \\
\text { Overall }\end{array}$ & \multicolumn{2}{|c|}{ Sex } & \multicolumn{2}{|c|}{ Residence } & \multicolumn{5}{|c|}{ Wealth Quintile } \\
\hline \multicolumn{12}{|l|}{ Industrialized } \\
\hline Belarus & MICS 2005 & 99 & 99 & 99 & 99 & 99 & 99 & 99 & 99 & 99 & 99 \\
\hline Bosnia and Herzegovina & MICS 2006 & 77 & 76 & 78 & 71 & 80 & 76 & 79 & 79 & 74 & 76 \\
\hline Moldova & DHS 2005 & 869093 & 90 & 90 & 90 & 89 & $::$ & 90 & 86 & 86 & 93 \\
\hline Montenegro & MICS 2005-06 & 71 & 69 & 74 & 71 & 72 & $::$ & $::$ & $::$ & $::$ & $::$ \\
\hline Serbia & MICS 2005-06 & 71 & 70 & 72 & 70 & 72 & 69 & 76 & 71 & 68 & 69 \\
\hline
\end{tabular}

* The prevalence $(\mathrm{P})$ with its $95 \%$ confidence interval (where available) is presented as $95 \% \mathrm{~L}$ P $95 \% \mathrm{U}$. See Louis TA, Zeger SL. Effective communication of standard errors and confidence intervals. Biostatistics, 2009, 10(1), 1-2.

** Preliminary survey results at the time of publication.

Note: Standard errors are not available for the prevalence of cardholders in all survey reports and thus confidence intervals are not provided here in some instances. The author encourages the reporting of standard errors for all estimates reported in DHS and MICS standard reports.

remain to redesign immunization or health cards in such a way to improve communication between all parties, closing gaps in communication between health care workers and parents, while also potentially streamlining workflow in health clinics or posts. Recent research in Pakistan has demonstrated the potential benefit on increased follow-up immunization visits (e.g., reduced drop-out) of redesigned, more mother-friendly immunization cards that incorporate a larger card size with bright colour and the strategic placement of reminder information in large text $[12,13]$. In addition, more needs to be done through training and mentoring of health care workers to improve caregivers' understanding of the card and the benefits of retaining and bringing the immunization card to all child health care encounters [14]. As a child-centred, parent-controlled piece of information, immunization cards can improve the health consciousness of parents (and health providers) by providing basic information such as date, day of the week and location of the next vaccination visit as well as other health information and instructions thereby inherently promoting child health within the family and giving parents the potential to play a large role in protecting and promoting the public's health.

Finally, immunization cards support the collection of data for uses other than direct clinical care or delivery of vaccines such as for quality management and public health monitoring. Periodic coverage surveys, through which information is collected directly from a sample of households, are one way in which immunization coverage of young children is monitored. Within these surveys, immunization or child health cards available in the household are used to collect documented information on immunization services received by children. In the absence of an available or completed card, surveys often collect information based on maternal recall, though there is mixed evidence regarding the validity and reliability of recall relative to health records or immunization cards [15-20]. Despite the importance of cards to monitoring, the reliance on cards as a source of immunization data will almost certainly underestimate coverage until the proportion of cardholders is more nearly equal the proportion of children immunized [21], further reinforcing the need to improve issuance, maintenance and utilization of cards.

Unfortunately, the prevalence of cardholders is surprisingly low in many countries. In 87 countries with readily available card prevalence data from Demographic and Health Surveys (DHS) or Multiple Indicator Cluster Surveys (MICS) since 2000, the median prevalence of cardholders is $72 \%$ (min: 8\%; max: 99; inter-quartile range: 59-82\%) (Table 1) (N.B., all data are available at www.measuredhs.com and www.childinfo.org/mics.html). Cardholder prevalence was $<50 \%$ in 17 of the 87 countries $(20 \%), 50-69 \%$ in 20 countries $(23 \%), 70-79 \%$ in 25 countries $(29 \%), 80-89 \%$ in 13 countries $(15 \%)$ and $>90 \%$ in 12 countries (14\%) (based on the most recent survey result for the 87 countries). The prevalence of cardholders was $<70 \%$ in 21 of the 33 least developed countries (according to World Bank classification [22]) represented in the Table $\mathbf{1}$ (median: 62\%; $\min$ : 8\%; $\max$ : 93\%; inter-quartile range: 48-74\%). Differences in cardholder prevalence between boys and girls, urban and rural areas, and across wealth quintiles varied across countries. Whether the low prevalence of cardholders reflects problems related to issuance or to lost or misplaced cards is unclear. Recent anecdotal reports of national immunization programmes failing to procure and distribute cards may also be a factor contributing to low prevalences in some areas.

In summary, despite its potential to provide an adequate record of immunization history and its potential contribution to child health as a source of health monitoring data, the child immunization card is too often underutilized or inappropriately used by parents and health care workers and therefore does not always fulfil its intended purpose. National immunization programmes should be encouraged to procure cards as an essential piece of equipment in conjunction with other necessary vaccination supplies (e.g., auto-disable syringes, safe injection supplies). Moreover, these programmes should be encouraged to more actively promote the issuance and maintenance of the card (i.e., the card must be retained) with appropriate instructions for the 
utilization of the card by parents and health care workers at each health care encounter and work to ensure accurate completion of the card by health care workers each time a child is immunized. The child immunization card is a relatively inexpensive intervention, and further research is needed to examine its potential role as a cost-effective means of improving immunization coverage. In addition, the global immunization community should begin to engage with the growing momentum of technology innovation and integration in public health to improve child immunization recording and monitoring of immunization status in the $21 \mathrm{st}$ century.

\section{DISCLAIMER}

The opinions expressed here are those of the author alone and do not necessarily reflect the positions of the United Nations Children's Fund.

\section{ACKNOWLEDGEMENTS}

The author is grateful to Drs Jos Vandelaer and Maritel Costales and Ms Stacy Young for their thoughtful comments on early versions of this manuscript.

\section{REFERENCES}

[1] World Health Organization. WHO recommendations for routine immunization - summary tables. Available from: http://www.who. int/immunization/policy/immunization_tables/en/ (accessed 1 October 2011).

[2] Khan MN, Rahman ML, Awal Miah A, Islam MS, Musa SA, Tofail F. Vaccination coverage survey in Dhaka District. Bangladesh Med Res Counc Bull 2005; 31(2): 46-53.

[3] Donald PR, Kibel MA. The child health card--a cornerstone of preventive and promotive paediatrics. S Afr Med J 1984; 65(11): 423-5.

[4] Crisp NG, Donald PR. The 'Road to Health' card and immunisation records. S Afr Med J 1987; 72(5): 331-3.

[5] Lawrence M. A computer generated patient carried health check card. J R Coll Gen Pract 1986; 36(291): 458-60.

[6] Mukanga DO, Kiguli S. Factors affecting the retention and use of child health cards in a slum community in Kampala, Uganda, 2005. Matern Child Health J 2006; 10(6): 545-52.

[7] Odusanya OO, Alufohai EF, Meurice FP, Ahonkhai VI. Determinants of vaccination coverage in rural Nigeria. BMC Public Health 2008; 8: 381 .
Ndiaye NM, Ndiaye P, Diédhiou A, Guèye AS, Tal-Dia A. [Factors related to failure to complete immunization of children aged 10-23 months in Ndoulo (Senegal)]. [Article in French] Sante 2009; 19(1): 9-13.

[9] Turner RC, Waivers LE, O'Brien K. The effect of patient-carried reminder cards on the performance of health maintenance measures. Arch Intern Med 1990; 150(3): 645-7.

[10] Tugumisirize F, Tumwine JK, Mworozi EA. Missed opportunities and caretaker constraints to childhood vaccination in a rural area in Uganda. East Afr Med J 2002; 79(7): 347-54.

[11] Khan MN, Rahman ML, Awal Miah A, Islam MS, Musa SA, Tofail F. Vaccination coverage survey in Dhaka District. Bangladesh Med Res Counc Bull 2005; 31(2): 46-53.

[12] Usman HR, Rahbar MH, Kristensen S, et al. Randomized controlled trial to improve childhood immunization adherence in rural Pakistan: redesigned immunization card and maternal education. Trop Med Int Health 2011; 16(3): 334-2.

[13] Usman HR, Akhtar S, Habib F, Jehan I. Redesigned immunization card and center-based education to reduce childhood immunization dropouts in urban Pakistan: a randomized controlled trial. Vaccine 2009; 27(3): 467-72.

[14] Harrison D, Heese HD, Harker H, Mann MD. An assessment of the 'road-to-health' card based on perceptions of clinic staff and mothers. S Afr Med J 1998; 88(11): 1424-8.

[15] George K, Victor S, Abel R. Reliability of mother as an informant with regard to immunisation. Indian J Pediatr 1990; 57(4): 588-90.

[16] Langsten R, Hill K. The accuracy of mothers' reports of child vaccination: evidence from rural Egypt. Soc Sci Med 1998; 46(9): 1205-12.

[17] Ndirangu J, Bland R, Bärnighausen T, Newell ML. Validating child vaccination status in a demographic surveillance system using data from a clinical cohort study: evidence from rural South Africa. BMC Public Health 2011; 11: 372.

[18] Shinall MC Jr, Plosa EJ, Poehling KA. Validity of parental report of influenza vaccination in children 6 to 59 months of age. Pediatrics 2007; 120(4): e783-7.

[19] Valadez JJ, Weld LH. Maternal recall error of child vaccination status in a developing nation. Am J Public Health 1992; 82(1): 120-2.

[20] Luman ET, Ryman TK, Sablan M. Estimating vaccination coverage: validity of household-retained vaccination cards and parental recall. Vaccine 2009; 27(19): 2534-9.

[21] Fisher A, Vaessen M. Measuring the prevalence of immunization. Int Health News [Abstract] 1987; 8(6): 1, 4.

[22] United Nations Development Policy and Analysis Division: The World Economic and Social Survey 2011. Available from: http:// www.un.org/en/development/desa/policy/wess/ (accessed 1 October 2011). 